Araştırma Makalesi / Research Article, Doğ Afet Çev Derg, 2021; 7(2): 382-391, DOI: 10.21324/dacd.907645

\title{
Oto Yıkama Atıksularının Klasik Fenton Prosesiyle Arıtımı: Ön Çöktürmenin KOI Giderim Kinetiği Üzerine Etkisi
}

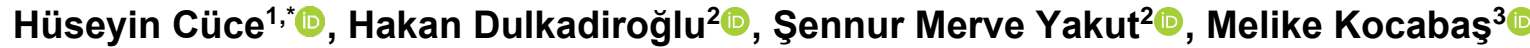 \\ ${ }^{1}$ Giresun Üniversitesi, Mühendislik Fakültesi, Harita Mühendisliği Bölümü, Giresun. \\ ${ }^{2}$ Nevşehir Hacı Bektaş Veli Üniversitesi, Mühendislik Mimarlık Fakültesi, Çevre Mühendisliği Bölümü, Nevşehir. \\ ${ }^{3}$ Kahramanmaraş Sütçü İmam Üniversitesi, Fen Bilimleri Enstitüsü, Çevre Mühendisliği Anabilim Dalı, Kahramanmaraş.
}

\section{Özet}

Nüfusa paralel olarak trafikteki araç sayısı da her geçen gün artmaktadır. Dolayısılla araçların yıkanmasından kaynaklanan atıksuların miktarı da önemli boyutlara ulaşmaktadır. Bu atıksuların çoğu evsel atıksu sinıfinda olmayıp doğrudan kanalizasyona verilmektedir. Bu çalışmada, 2 farklı oto ylkama tesisine ait 4 tip (ham ve ön çökeltim uygulanmış) atıksuda kimyasal oksijen ihtiyacı (KOI) giderimi amacıyla klasik Fenton prosesi uygulanmıștır. Deneysel çalıșmalar sonunda sabit pH $=3$ değerinde, optimum kimyasal dozlar; 1 nolu tesisten alınan ham atıksu için: $\left[\mathrm{Fe}^{+2}\right]=100 \mathrm{mg} \mathrm{L}^{-1},\left[\mathrm{H}_{2} \mathrm{O}_{2}\right]=200 \mathrm{mg} \mathrm{L}$-1 ve ön arttım uygulanan örnek için bu değerler $\left[\mathrm{Fe}^{+2}\right]=75 \mathrm{mg} \mathrm{L} \mathrm{L}^{-1},\left[\mathrm{H}_{2} \mathrm{O}_{2}\right]=150 \mathrm{mg} \mathrm{L} \mathrm{L}^{-1}$ olarak tespit edilirken, 2 nolu tesisten alınan ham atıksu için $\left[\mathrm{Fe}^{+2}\right]=100 \mathrm{mg}$ $L^{-1},\left[\mathrm{H}_{2} \mathrm{O}_{2}\right]=225 \mathrm{mg} \mathrm{L}^{-1}$, ön çökeltim uygulandıktan sonra ise $\left[\mathrm{Fe}^{+2}\right]=75 \mathrm{mg} \mathrm{L}^{-1},\left[\mathrm{H}_{2} \mathrm{O}_{2}\right]=100 \mathrm{mg} \mathrm{L}^{-1}$ olarak belirlenmiştir. Prosesin arıtım verimliliği değerlendirildiğinde, optimum koşullarda KOİ giderimi 1. Atıksu örneği için sirastyla, \%86 ve \%89 iken 2. örnekte ise bu değerler sirasıyla \%90 ve \%98'dir. Reaksiyon kinetiği incelendiğinde, ham atıksularda oksidasyon mekanizmasinın genel itibariyle 2. derece kinetiğe uygun olduğu görülse de $\left(R^{2}=0,55\right.$ ve 0,95$)$ ön çöktürme sonrası ayrlşma mekanizmasının BMG kinetik modeline daha fazla uyum gösterdiği $\left(R^{2}=0,99\right)$ ortaya çıkarılmıștır.

\section{Treatment of Auto Wash Wastewater with Classical Fenton Process: Effect of Pre- Settling on COD Removal Kinetics}

\begin{abstract}
In parallel with the population, the number of vehicles in traffic is increasing day by day. Therefore, the volume of wastewater generated by vehicle cleaning reaches substantial proportions. While most of these wastewaters are not classified as domestic wastewater, they are directly discharged to the sewerage. In this study, classical Fenton process was applied to remove chemical oxygen demand (COD) from 4 types (raw and pre-treated) wastewater belonging to 2 different car wash plants. At the end of experimental studies, optimum chemical doses at a constant $\mathrm{pH}=3$ value; for the sample taken from the lnd plant without presettling: $\left[\mathrm{Fe}^{+2}\right]=100 \mathrm{mg} \mathrm{L}^{-1},\left[\mathrm{H}_{2} \mathrm{O}_{2}\right]=200 \mathrm{mg} \mathrm{L^{-1 }}$ and for the sample treated with pretreatment these values $\left[\mathrm{Fe}^{+2}\right]=75 \mathrm{mg} \mathrm{L^{-1 }}$, $\left[\mathrm{H}_{2} \mathrm{O}_{2}\right]=150 \mathrm{mg} \mathrm{L}^{-1}$, for the raw wastewater sample taken from the 2 nd plant, $\left[\mathrm{Fe}^{+2}\right]=100 \mathrm{mg} \mathrm{L}^{-1},\left[\mathrm{H}_{2} \mathrm{O}_{2}\right]=225 \mathrm{mg} \mathrm{L^{-1 }}$, after presettling whereas $\left[\mathrm{Fe}^{+2}\right]=75 \mathrm{mg} \mathrm{L^{-1 }},\left[\mathrm{H}_{2} \mathrm{O}_{2}\right]=100 \mathrm{mg} \mathrm{L^{-1 }}$. COD removal in ideal conditions for the first wastewater sample is 86 percent and 89 percent, respectively, while these values are 90 percent and 98 percent for the second sample. The oxidation process in raw wastewater was found to be generally appropriate for 2 nd order kinetics $\left(R^{2}=0.55\right.$ and 0.95$)$, but the decomposition mechanism after pre-settling was found to be more consistent with the BMG kinetic model $\left(R^{2}=0.99\right)$.
\end{abstract}

$\underline{\text { Keywords }}$

Car Wash Wastewater, Fenton Process, COD, Advanced Oxidation

\section{Giriş}

Araç yıkama istasyonlarında yıkama işlemi elle (manuel) veya otomatik olarak yapılabilmekte ve her yıkamada ortalama $200 \mathrm{~L}$ su tüketilmektedir (Boluarte vd. 2016). Özellikle şehir dışında, kanalizasyon altyapısının bulunmadığı bölgelerdeki işletmelerde araç yıkamadan kaynaklanan atıksular genellikle herhangi bir arıtmaya tabi tutulmadan, doğrudan yeraltı veya akarsu, göl gibi alıcı su ortamlarına deşarj edilmektedir (Hamada ve Miyazaki 2004). Ancak yüksek oranda katı madde, yüzey aktif madde, yă̆ ve gres içerebilen bu atıksuların uygun şekilde arıtılması gereklidir. Böylece çevresel kontaminasyonun önüne geçilebilir ve yeniden kullanımı ile su kıtlığının azaltılmasına katkı verilebilir (Sarmadi vd. 2020; Lau vd. 2013). 
Amerika Çevre Ajansı (USEPA) tarafından araç yıkama sularındaki deterjan, ağır metal, yağ, gres, polisiklik aromatik hidrokarbonlar (PAH) ve uçucu organik bileşikler ve benzeri toksik ve/veya kanser yapıcı kirletici bazı maddelerin listesi oluşturularak farkındalığın artmasına çalışılmıştır (Oknich 2002; Lan vd. 2009; Bhatti vd. 2011). Katı maddeler ve serbest yağ basit fiziksel proseslerle giderilebilirken, çözünmüş organik kirleticilerin arıtılabilmesi için çeşitli yöntemler; adsorpsiyon, nanofiltrasyon, elektrokoagülasyon, katalitik oksidasyon, Fenton ve radikallere dayalı elektrokimyasal prosesler yüksek verimlilik ve işletme hızlarında uygulanabilmektedir (Onaran vd. 2020; Şentürk ve Y1ldız 2020; Kalipci vd. 2016; Argun vd. 2017; Gönder vd. 2020; Tony ve Lin 2020; Kashi vd. 2021).

İleri Oksidasyon Prosesleri (IOP), toksik ve kalıcı özellikteki organik maddeleri hiçbir ayrım yapmadan zararsız son ürünlere dönüştürebilmekte ve atıksuların yeniden kullanılabilmesi için firsat oluşturmaktadır. Fenton oksidasyonu, zor ayrıştırılabilir, refrakter, toksik ve renkli endüstriyel atık suları arıtabilme kabiliyetinden dolayı çok çeşitli atıksu tipleri için iyi bir alternatiftir. Seçici olmayan ve hızlı bir şekilde su ortamındaki organik kirliliği okside edebilen • OH gibi reaktif türlerinin oluşumuna dayanan bu proses; UV; UV/ $\mathrm{H}_{2} \mathrm{O}_{2} ; \mathrm{H}_{2} \mathrm{O}_{2} / \mathrm{Fe}^{2+}$ (Fenton prosesi), $\mathrm{H}_{2} \mathrm{O}_{2} / \mathrm{Fe}^{\mathrm{o}}$ (Fentonbenzeri), $\mathrm{UV} / \mathrm{H}_{2} \mathrm{O}_{2} / \mathrm{Fe}^{2+}$ (Foto-Fenton prosesi) gibi değişik modifikasyonlarda uygulanabilmektedir (Gökkus ve Ciner 2010; Üstün vd. 2010; Özdemir vd. 2011; Kocakaplan vd. 2014; Gamaralalage vd. 2019; Moazzem vd. 2020; Cüce ve Aydın Temel 2021). Ancak uygun arıtma yönteminin seçiminde verimlilik kadar işletme kolaylığı da göz önünde tutulması gereken önemli bir faktördür. Oto yıkama atıksuları gibi yüksek katı madde içeriğine sahip atıksuların ön çöktürme sonrası ileri arıtım prosesine iletilmesi, işletmenin verimliliği ve sürdürülebilirliği açısından önemlidir.

Genel tanım olarak Fenton prosesi, güçlü asidik şartlar altında, $\mathrm{Fe}^{2+}$ katalizörü bulunan ortama hidrojen peroksit ilave edilmesiyle hidroksil radikallerinin ortaya çıması ve bu hidroksil radikallerinin de ortamda bulunan kirleticileri yükseltgemesine dayanmaktadır. Bu tanımda bahsedilen klasik ya da diğer bir deyişle konvansiyonel Fenton prosesi aşağıdaki reaksiyon denklemleri (Eşitlik 1 ve 2) ile açıklanmakta ve kinetik hızları literatürde kapsamlı olarak verilmektedir (Sychev ve Isak 1995; Bayat 2013).

$\mathrm{Fe}^{+2}+\mathrm{H}_{2} \mathrm{O}_{2} \rightarrow \mathrm{Fe}^{+3}+\bullet \mathrm{OH}+\mathrm{OH}^{-}$

Oluşan hidroksil radikalleri daha sonra ortamdaki ferröz demir ile reaksiyona girer ve +3 değerlikli ferrik $\left(\mathrm{Fe}^{3+}\right)$ iyonlar açığa çıkar (Eşitlik 2):

- $\mathrm{OH}+\mathrm{Fe}^{2+} \rightarrow \mathrm{OH}^{-}+\mathrm{Fe}^{3+}$

Bu aşamadan sonra ortamın pH'sı nötr seviyelere getirilir ve floklaşma meydana gelir. Oluşan floklar bir süre sonra çökelmeye başlar ve dipte bir çamur tabakası olarak birikir. Burada oluşan ilave çamur, Fenton prosesinin bir dezavantajı olarak görülmektedir.

Literatürde yer alan çalışmalar genel olarak değerlendirildiğinde, araç yıkama atıksularının arıtımında birbirinden oldukça farklı arıtma yöntemlerinin denendiği ve çoğunda yüksek giderim verimleri elde edildiği görülmektedir. Hamada ve Miyazaki (2004), oto yıkama atıksularının arıtılarak tekrar kullanımı için flokülasyon ve aktif karbon prosesleri ile takviye edilmiş membran ultrafiltrasyonunu denemişler ve Kimyasal Oksijen İhtiyacı (KOİ) konsantrasyonunu 3.7 - $15.7 \mathrm{mg} \mathrm{L}^{-1}$ aralı̆ğına kadar düşürmüşlerdir. Lau vd. (2013)'de oto yıkama atıksularına ultrafiltrasyon ve nanofiltrasyon uygulamıs, en yüksek KOİ giderimini NF270 membran ile \%70.9 - 91.5 aralığında elde etmişlerdir. Bhatti vd. (2011) yaptıkları çalışmada oto yıkama atıksuyunun arıtımında havalandırma, alum ile koagülasyon ve hidrojen peroksit ile oksidasyondan oluşan 3 aşamalı entegre bir proses denemişler, \% 93 oranında KOİ giderimi elde etmişlerdir. Emamjomeh vd. (2019) ise manuel oto yıkama işletmesi atıksuyuna uyguladıkları elektrokoagülasyon/flotasyon, çöktürme ve filtrasyon adımlarından oluşan arıtma prosesinde farklı akım şiddeti $(1-2$ A), elektroliziz süresi $(30-90 \mathrm{dk})$ ve $\mathrm{pH}(5-9)$ değerleri ile 20 adet laboratuvar çalışması yapmışlardır. Çalışmada en yüksek giderim verimleri KOİ için \%94.5, bulanıklık için \% 95 ve yüzey aktif madde (MBAS - Methylene Blue Active Substances) için \% 95.2 olarak belirlenmiştir. Araç yıkama atıksuları için elektrooksidasyon (EO), hidrojen peroksit ile elektrooksidasyon $\left(\mathrm{EO}-\mathrm{H}_{2} \mathrm{O}_{2}\right)$ ve elektro-Fenton $(\mathrm{EF})$ prosesi gibi elektrokimyasal ileri oksidasyon yöntemleri de denenmiş ve başarılı sonuçlar alınmıştır. Araştırmacılar, EF prosesinde daha hızlı ve yüksek olmakla birlikte, tüm proses alternatiflerinde KOİ ve anyonik yüzey aktif maddelerin tamamen giderilebildiğini göstermiştir (Ganiyu vd. 2018). Gönder vd. (2017) Fe ve Al elektrodların kullanıldığı elektrokimyasal yöntemle oto yıkama atıksuyunun arıtımını araştırmışlar, optimum koşullarda her iki elektrod ile \% 88 KOİ giderimi elde etmişlerdir. Elektrokimyasal yöntemin uygulandığı bir diğer çalışma ise Panizza ve Cerisola (2010) tarafından yapılmıştır. Araştırmacılar kurşun dioksit ve bor katkılı elmas (BKE) elektrodların verimini karşılaştırmış; her iki elektrod ile de KOİ'nin tamamının giderildiğini fakat BKE elektrodun daha kısa sürelerde giderimi tamamladığını tespit etmişlerdir. Oto yıkama atıksularının tekrar kullanımı amacıyla kimyasal koagülasyon ve membran biyoreaktör proseslerinin kullanıldı ğı arıtma çalışması Boluarte vd. (2016) tarafindan yürütülmüş ve \%100 AKM, \%99.2 KOİ, \% 41 amonyak giderimi elde edilerek geri kazanım için yeterli arıtmanın sağlandığı rapor edilmiştir. Bu çalışmada oto yıkama atıksularının bir ileri oksidasyon yöntemi ile arıtımı için laboratuvar ölçeğinde gerçek atıksu örneklerinde denemeler yapılmıştır. Küçük ölçekli tesislerde dahi uygulama kolaylığı ve verim açısından avantajlı olabileceği öngörülen Fenton prosesi için optimum koşullar test edilmiş ve ön çöktürmenin arıtılabilirlik verimine etkisi değerlendirilmiştir. 
Ön çöktürme işleminin arıtımın yükünü ne kadar azalttığı ve/veya kimyasal oksidasyon öncesi organik kirleticilerin kısmen uzaklaştırılmasının arıtma kabiliyetini ne kadar arttırdığına dair literatürde sınırlı bilgi mevcuttur. Yüksek miktarlarda kirletici içerebilen bu atıksuların yoğun askıda katı madde içeriklerini azaltmak için ön çöktürme uygulanması ve arıtma performansına etkisinin değerlendirilmesi çalışmanın odak noktasıdır. Bu amaçla, konvansiyonel Fenton prosesi için kesikli sistem kullanılmış ve izleyici parametre olarak KOİ seçilmiştir. Farklı tesislerden toplanan atıksu örneklerinin optimum $\mathrm{pH}$ değerinde, katalizör ve hidrojen peroksit konsantrasyonlarının arıtma performansına etkileri incelenmiştir. Deneysel proses izleme süreci; ön çökeltim işlemi öncesi ve sonrasında, KOİ gideriminin optimum süre ve kimyasal dozlama koşullarında kinetiği hesaplanmış en uygun reaksiyon kinetiği modelleri için karşılaştırmalar yapılmıştır.

\section{Materyal ve Yöntem}

\subsection{Atıksu Karakterizasyonu}

Çalışmada kullanılan atıksular iki farklı oto yıkama tesisinden (Nevşehir il sınırları içinde faaliyet gösteren) 12 saatlik kompozit örnekleme ile temin edilmiş ve soğutucu kutular içinde muhafaza edilerek laboratuvar ortamına getirilmiştir. Tesislerden alınan örnekler herhangi bir işleme tabi tutulmamışken, fazla miktarda yüzer madde ve askıda katı içermektedirler. Deneysel çalışmalarda kullanılan atıksulara ait karakterizasyonlar Tablo 1'de verilmiştir. Her bir tesisten örneklenen atık sularda fiziko-kimyasal özellikleri tespit etmek için 3 tekrarlı olarak test kitleri (Toplam azot Hach Laton LCK238, Toplam fosfor Hach Lange LCK348) kullanılarak analizler yapılmıştır. Çalışmada ön arıtımın, arıtıma etkisini belirleyebilmek için ham atıksu örneklerine ön çökeltme uygulanmıştır (Imhoff konisinde 4 saatlik beklemeye alınarak). Daha sonra tüm örnekler ileri oksidasyon işlemine tabi tutulmuştur.

Tablo 1: Oto yıkama atıksularının karakterizasyonlar

\begin{tabular}{|c|c|c|c|c|}
\hline Parametre & $\begin{array}{l}\text { Tesis-1 } \\
\text { Ham Atıksu }\end{array}$ & $\begin{array}{l}\text { Tesis-1 } \\
\text { Ön Çökeltme } \\
\text { uygulanmış }\end{array}$ & $\begin{array}{l}\text { Tesis-2 } \\
\text { Ham Atıksu }\end{array}$ & $\begin{array}{l}\text { Tesis-2 } \\
\text { Ön Çökeltme } \\
\text { uygulanmış }\end{array}$ \\
\hline $\mathrm{pH}$ & $7.84 \pm 0.20$ & $8.84 \pm 0.28$ & $7.68 \pm 0.18$ & $7.95 \pm 0.35$ \\
\hline ORP, mV & $5.40 \pm 0.25$ & $4.60 \pm 0.25$ & $5.90 \pm 0.16$ & $5.60 \pm 0.30$ \\
\hline $\mathrm{KOI}, \mathrm{mg} \mathrm{L}^{-1}$ & $4369 \pm 88$ & $495 \pm 49$ & $5022 \pm 94$ & $567 \pm 33$ \\
\hline Toplam Azot, mg L $\mathrm{L}^{-1} \mathrm{~N}$ & $25.8 \pm 1.62$ & $9.85 \pm 0.90$ & $17.5 \pm 1.10$ & $8.48 \pm 0.66$ \\
\hline Toplam Fosfor, $\mathrm{mg} \mathrm{L}^{-1} \mathrm{PO}_{4}-\mathrm{P}$ & $12.5 \pm 0.55$ & $6.40 \pm 0.44$ & $10.4 \pm 0.86$ & $2.04 \pm 0.08$ \\
\hline
\end{tabular}

Deneysel çalışmalarda kullanılan kimyasallar Merck ve Sigma-Aldrich (Almanya) firmalarından temin edilmiş olup analitik saflık derecesindedir. Ayrıca deney çözeltilerinin hazırlanmasında ultra saf su cihazından (MP Minipure) elde edilen saf su kullanılmıştır.

\subsubsection{Deneysel Çalışma}

Deneyler MTops jar-test cihazında, 100 mL'lik numuneler üzerinde yürütülmüştür. Genel olarak, atıksu arıtımında Fenton reaksiyonunun $\mathrm{pH}=3$ değerinde oldukça etkin olduğu kanıtlanmıştır (Baştürk ve Karataş 2014; Kaya ve Aşçı 2019). Başlangıç pH değeri 3'e sülfürik asit ve sodyum hidroksit çözeltileriyle pH probu (Mettler-Toledo) vasıtasıyla ayarlanmıştır. Ardından farklı dozlarda $\mathrm{FeSO}_{4} \cdot 7 \mathrm{H}_{2} \mathrm{O}$ ile $\mathrm{H}_{2} \mathrm{O}_{2}$ ilave edilmiştir. Reaksiyon $\mathrm{H}_{2} \mathrm{O}_{2}$ eklenmesiyle birlikte başlamıştır. Jar-test cihazında 200 devir/dk'da 2 dakika ve ardından 90 devir/dk'da 40 dakika karıştırma işlemi uygulanmıştır. Hızlı ve yavaş karıștırmanın ardından karıştırma durdurularak $\mathrm{Fe}(\mathrm{OH})_{3}$ floklarının oluşup çökelmesi için çözeltinin pH'sı 7.5 - 8.0 aralığına getirilmiştir. Çökelmeden sonra $4000 \mathrm{rpm}$ de santrifüj (Nüve) edilerek duru fazdan 25 mL alınarak KOİ değeri ölçülmüştür. KOİ analizi, Hach-Lange test kitleri ile gerçekleştirilmiştir. Hach LT200 termo-reaktörü kullanılarak sindirilen örnekler soğutulduktan sonra, Hach Lange DR 3900 model spektrofotometrede absorbans ölçümleri gerçekleştirilmiştir.

\section{Bulgular ve Tartışma}

\subsection{Demir Konsantrasyonunun Etkisi}

Fenton prosesinde katalizör olarak kullanılan demir, reaksiyon verimi açısından önemlidir. Çünkü $\mathrm{Fe}^{2+}, \mathrm{H}_{2} \mathrm{O}_{2}{ }^{\prime} \mathrm{yi}$ bileşenlerine ayrıştırarak radikal oluşumunu sağlamaktadır. Bu da, ferro demir $\left(\mathrm{Fe}^{2+}\right)$ konsantrasyonu ne kadar fazlaysa o kadar çok hidroksil radikali oluşacağı anlamına gelmektedir. Genel olarak demir konsantrasyonu arttığında organik madde ayrışma hızı da artar. Fakat reaksiyon belirli bir doygunluğa ulaştıktan sonra $\mathrm{Fe}^{2+}$ ortamdaki hidrojen peroksitlerle daha fazla reaksiyona giremez ve bu aşamadan sonra verim artışı gözlenemez (Bello vd. 2018). 
Fenton reaksiyonunun gerçekleşebilmesi için gerekli en uygun $\mathrm{Fe}^{+2}$ dozunu belirlemek üzere, her numuneden $100 \mathrm{~mL}$ alınarak, pH 3 ve $50 \mathrm{mg} \mathrm{L}^{-1}$ sabit peroksit ilavesiyle $50-200 \mathrm{mg} \mathrm{L}^{-1}$ aralığındaki farklı $\mathrm{Fe}^{2+}$ konsantrasyonları için testler yapılmış ve KOİ giderim verimleri elde edilmiştir. Arıtım verimindeki değişim Şekil 1'de görülmektedir.

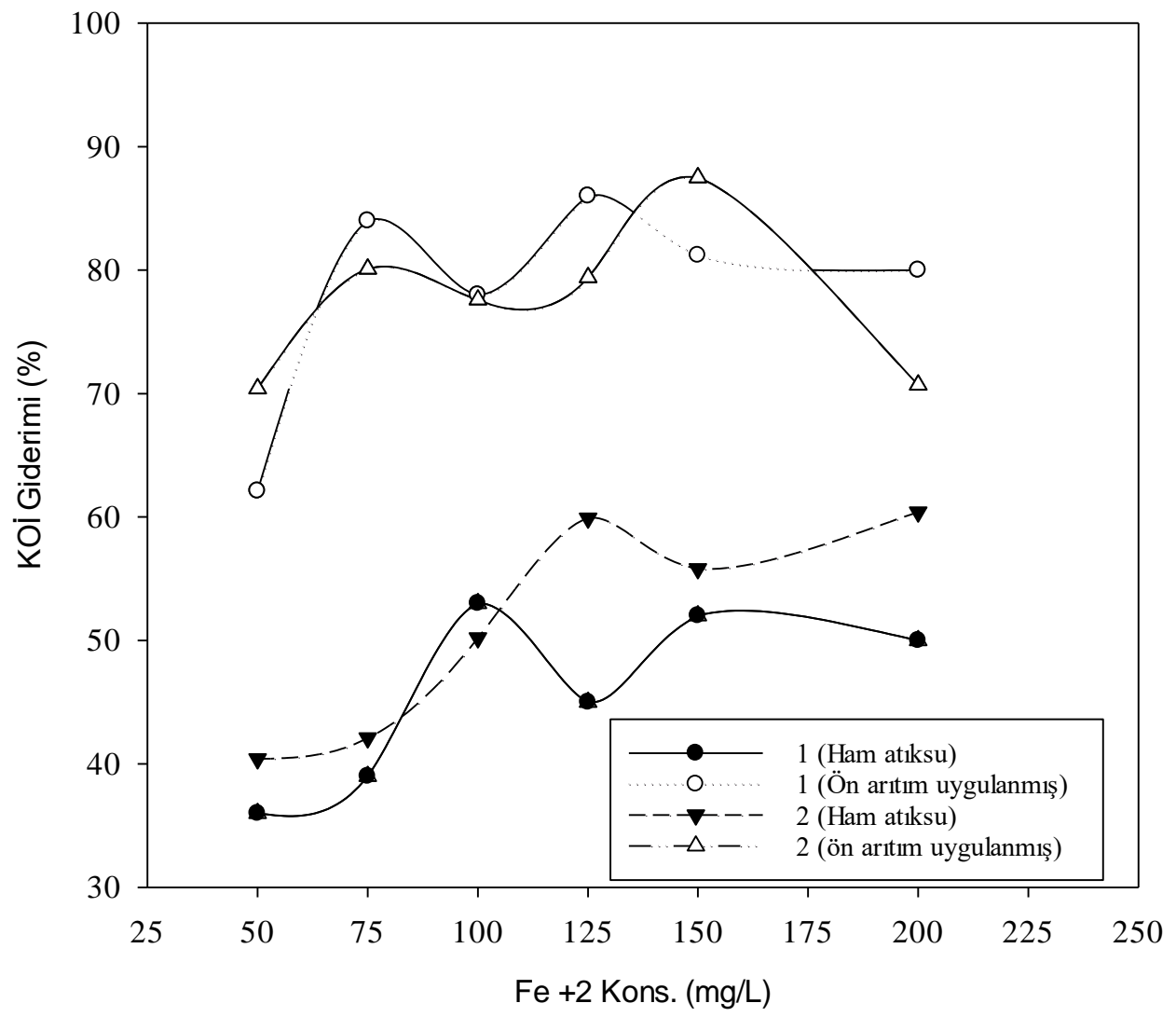

Şekil 1: Farklı $\mathrm{Fe}^{2+}$ konsantrasyonlarında KOI giderim verimleri

Şekil 1'de görüldüğü gibi, 1 ve 2 nolu ham atıksu örnekleri için $100 \mathrm{mg} \mathrm{L}^{-1} \mathrm{Fe}^{2+}$ miktarı, ön arıtım uygulanmış örneklerde ise $75 \mathrm{mg} \mathrm{L}^{-1}$ 'nin üzerindeki $\mathrm{Fe}^{2+}$ dozları KOİ giderim verimini arttırmamaktadır ve arıtımın verim stabilitesi gözlenememektedir. Çünkü demir bir noktadan sonra doygunluğa ulaşmakta ve dolayısıyla ortamdaki hidrojen peroksit ile tepkimeye girememektedir. Bunlara ek olarak fazla demir sülfat koagülasyonu arttırdığından, çökelen çamur miktarı da artış göstermiştir.

Boyar madde içeren endüstriyel atıksulardan (kağıt endüstrisi gibi) Fenton prosesiyle renk ve KOİ gideriminin araştırıldığı ileri oksidasyon çalışmalarında (Dolay 2009; Ertugay ve Acar 2017; Kaya ve Aşçı 2019), başlangıç demir konsantrasyonu denemesinde belirli bir dozdan sonra giderim verimlerinin sabitlendiği ve aşırı miktarda demirin reaksiyon sonunda fazla miktarda çamur oluşturabileceği görülmüştür.

\section{2. $\mathrm{H}_{2} \mathrm{O}_{2}$ Konsantrasyonunun Etkisi}

Fenton prosesinde organik madde ayrışmasında etkin rol oynayan bir diğer önemli parametre hidrojen peroksit konsantrasyonudur (Babuponnusami ve Muthukumar 2014). Ortamdaki katalizörle reaksiyona giren hidrojen peroksit (Eşitlik 1) sonucunda ortaya çıkan hidroksil radikalleri ortamda bulunan organik kirleticileri parçalamaktadır (Eşitlik 3).

$\mathrm{RH}+\bullet \mathrm{OH} \rightarrow \mathrm{H}_{2} \mathrm{O}+\bullet \mathrm{R}$

Hidrojen peroksit miktarı arttıkça sistemin verimi de artmaktadır fakat belirli bir değerden yüksek peroksit negatif etki oluşturur. Ortamdaki hidroksil radikalleri, hidroperoksil radikalleri ile etkileşime girerek peroksitin yeniden oluşumuna yol açar ki bu da etkin hidroksil radikali miktarını azaltarak giderim verimini düşürür (Brito vd. 2010). Bu yüzden hidrojen peroksitin optimize edilmesi oldukça önemlidir. Bu amaçla pH 3'te ön arıtım uygulanmayan ham atıksular için optimum $\mathrm{Fe}^{+2}: 100 \mathrm{mg} \mathrm{L}^{-1}$ ve diğer ön çökeltime tabi tutulmuş örnekler için optimum $75 \mathrm{mg} \mathrm{L}^{-1}$ demir konsantrasyonunda, farklı $\mathrm{H}_{2} \mathrm{O}_{2}$ dozları ile denemeler gerçekleştirilmiştir. Elde edilen sonuçlar Şekil 2'de gösterilmektedir. 


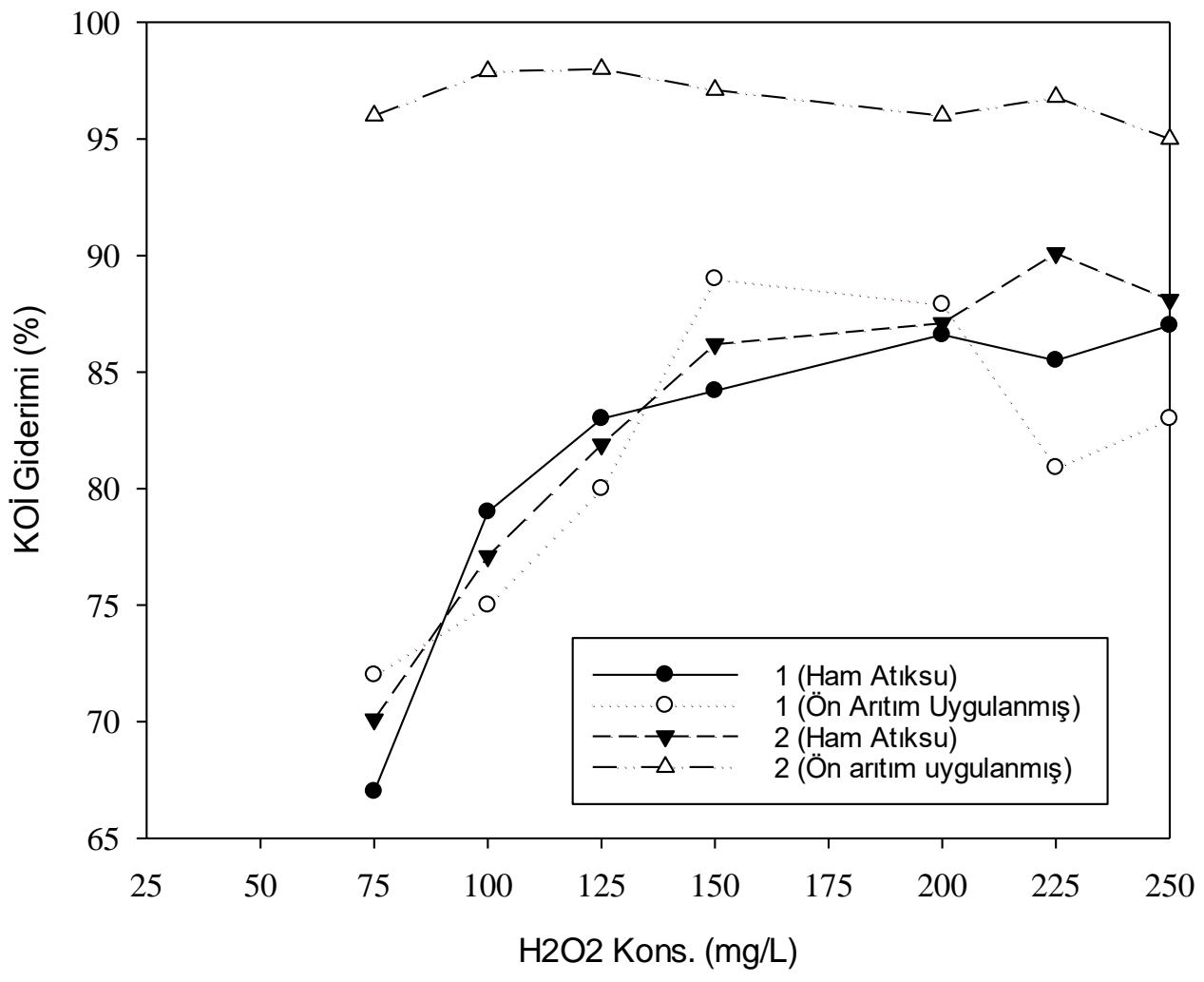

Şekil 2: Hidrojen peroksit dozunun KOI giderimine etkisi

Şekil 2'de görüldüğü gibi özellikle ham atıksu numunelerinde sırasıyla 1. Numune: $200 \mathrm{mg} / \mathrm{L}$ ve 2 . Numune: $225 \mathrm{mg} / \mathrm{L}$ hidrojen peroksit ilavesine kadar verim aşama aşama artıp bu değerden sonra düşmeye başlamıştır. Verimin düşmeye başladığı bu nokta, hidrojen peroksitin fazlalığını ifade etmektedir. Aşırı dozlanan hidrojen peroksit, ortamda oluşan $\mathrm{OH}^{*}$ radikallerinin azalmasına yol açarak oksidasyon hızını yavaşlatıcı radikal süpürücü bir etki gösterdiği düşünülmektedir. Organik kirleticilerin ayrışması için yetersiz kalan oksidant madde nedeniyle KOİ gideriminin de düştüğü benzer çalışmalarda gözlenmiştir (Argun 2012; Chu vd. 2012). Benzer durum çökeltme işlemiyle KOİ yükü kısmen azaltılan örnekler için de geçerlidir. Bu numunelerde sırasıyla 150 ve $100 \mathrm{mg} / \mathrm{L}$ peroksit dozlarından sonra verim artışı durmuştur. Dolayısıyla Fenton reaksiyonundan yüksek verim alınabilmesi için fazla $\mathrm{H}_{2} \mathrm{O}_{2}$ 'nin hidroksil radikalleri üzerinde süpürme etkisinin oluştuğu göz ardı edilmemelidir. Bu çalışmada ön arıtım uygulanmış her iki örnek için kritik peroksit ilavesinden sonra giderim veriminde artış gerçekleşmediği noktadaki 1 . ve 2 . numuneler için peroksit miktarları sırasıyla; $150 \mathrm{mg} \mathrm{L}^{-1}$ ve $100 \mathrm{mg} \mathrm{L}^{-1}$ optimum dozlar olarak kabul edilmiştir.

\subsection{Kinetik Çalışma}

Yapılan deneysel çalışmalar sonucunda optimum deneysel koşullar 1 nolu tesise ait ham atıksu için: $\left[\mathrm{Fe}^{2+}\right]=100 \mathrm{mg} \mathrm{L}{ }^{-1}$ ve $\left[\mathrm{H}_{2} \mathrm{O}_{2}\right]=200 \mathrm{mg} \mathrm{L}^{-1}$; ön arıtımlı 1. Numune için ise: $\left[\mathrm{Fe}^{2+}\right]=75 \mathrm{mg} \mathrm{L}^{-1}$ ve $\left[\mathrm{H}_{2} \mathrm{O}_{2}\right]=150 \mathrm{mg} \mathrm{L}^{-1}$ iken 2 nolu tesise ait ham atıksu için $\left[\mathrm{Fe}^{2+}\right]=100 \mathrm{mg} \mathrm{L}^{-1}$ ve $\left[\mathrm{H}_{2} \mathrm{O}_{2}\right]=225 \mathrm{mg} \mathrm{L}^{-1}$ ve ön çökeltme uygulanmış 2 . Numune için ise $\left[\mathrm{Fe}^{2+}\right]=75$ $\mathrm{mg} \mathrm{L}^{-1}$ ve $\left[\mathrm{H}_{2} \mathrm{O}_{2}\right]=100 \mathrm{mg} \mathrm{L}^{-1}$ olarak belirlenmiştir. Bu koşullarda zamana karşı KOİ giderim veriminin takip edildiği kinetik çalışmalar yürütülmüş ve arıtım prosesine en uygun kinetik modeller belirlenmiştir. Bu kapsamda en uygun deneysel koşullar altında $45 \mathrm{dk}$. boyunca belirli sürelerde $(5-10-15-20-30-45$. dk) üst fazdan alınan $25 \mathrm{~mL}$ örnek santrifüj edilerek KOİ ölçümleri gerçekleştirilmiştir.

Laboratuvar testlerinde izleyici parametre olarak KOİ için hesaplanan giderim verim değerleri kullanılarak, fenton reaksiyonu için kinetik model belirleme çalışması gerçekleştirilmiştir. Bu kapsamda sıfırıncı (Eşitlik 4), birinci (Eşitlik 5) ve ikinci (Eşitlik 6) derece kinetik modellemesi yapılmıştır. Aşağıda kinetik denklemler ve ifade edilişleri gösterilmektedir (Kumar vd. 2008; Argun 2012).

0. Derece kinetik denklemi: $\frac{d c}{d t}=-k_{0}$

1. Derece kinetik denklemi: $\frac{d c}{d t}=-k_{1} C$

2. Derece kinetik denklemi: $\frac{d c}{d t}=-k_{2} C^{2}$ 
Burada $\mathrm{k}_{0}, \mathrm{k}_{1}, \mathrm{k}_{2}$, sırasıyla 0., 1. ve 2. Derece başlangıç kinetik sabitini, t, oksidasyon süresini ifade etmektedir. C, herhangi bir zamandaki KOİ konsantrasyonu, $\mathrm{C}_{0}$ ise başlangıçtaki KOİ konsantrasyonunu belirtmektedir. Yukardaki eşitliklerde tanımlamaları yapılan her 3 kinetik model denklemleri, integrasyonla sırasıyla Eşitlik 7, 8 ve 9'da verilen denklemlere dönüştürülebilirler.

$$
\begin{aligned}
& C t=C_{0}-k_{0} t \\
& C t=C_{0} e^{-k_{1} t} \\
& \frac{1}{C t}=\frac{1}{C o}+k_{2} t
\end{aligned}
$$

Burada $\mathrm{C}$, KOİ konsantrasyonu olup, $\mathrm{t}$ ise reaksiyon zamanını göstermektedir. Zamana karşı KOİ giderim verimleri boyutsuz $\mathrm{C} / \mathrm{C}_{0}$ değerleri olarak gösterilmekte ve aynı zamanda hızlı oksidasyon aşamasının başladığı zamanı da göstermektedir. Buna göre ilk 5 dakikada büyük miktarda KOİ giderimi sağlanmaktadır. $\mathrm{Fe}^{+2}$ ve $\mathrm{H}_{2} \mathrm{O}_{2}$ parametrelerinin başlangıç konsantrasyonları oksidasyon hızını doğrudan etkiler. Sonrasında $\mathrm{Fe}^{+2}$ ye yeniden dönüşüm yavaşlar, dolayısıyla reaksiyon hızı da azalır (Babuponnusami ve Muthukumar 2014).

Elde edilen $R^{2}$ değerine (determinasyon katsayısı) göre çalışılan tüm oto yıkama atıksuları için 0. , 1 . ve 2 . derece ayrışma mekanizmaları arasında en uygun kinetik model 2. derece kinetik olarak belirlenmiştir. Çünkü $R^{2}$ değeri ne kadar 1'e yakınsa hatanın o kadar düşük olduğu kabul edilmektedir. Çalışmada kullanılan her atıksu için hesaplanan 0., 1. ve 2. derece kinetik model ve korelasyon sonuçları Tablo 2'de gösterilmektedir.

Tablo 2: Kinetik Modellerden Elde Edilen Korelasyon Sonuçları

\begin{tabular}{llllll}
\hline Numune No & $\mathbf{0 . d e r e c e}\left(\boldsymbol{R}^{\mathbf{2}}\right)$ & $\boldsymbol{k}_{\mathbf{1}} / \mathbf{d k}^{-\mathbf{1}}$ & $\mathbf{1 . d e r e c e}\left(\boldsymbol{R}^{\mathbf{2}}\right)$ & $\boldsymbol{k}_{\mathbf{2}} / \mathbf{M}^{-\mathbf{1}} \mathbf{d k}^{\mathbf{- 1}}$ & $\mathbf{2 . d e r e c e}\left(\boldsymbol{R}^{\mathbf{2}}\right)$ \\
\hline 1 (ham atıksu) & 0.3058 & -0.0275 & 0.3952 & 0.0002 & 0.5556 \\
1 (ön çökeltme) & 0.5571 & -0.0356 & 0.6639 & 0.0004 & 0.9776 \\
2 (ham atıksu) & 0.4242 & -0.0422 & 0.7020 & 0.0004 & 0.9538 \\
2 (ön çökeltme) & 0.4220 & -0.0332 & 0.5828 & 0.0002 & 0.9613 \\
\hline
\end{tabular}

Bu ayrışma kinetik modellerine ek olarak Behnajady vd. (2007) yılında yaptıkları bir çalışmada kullanmış oldukları bir kinetik model (BMG, Eşitlik 10) üzerine de hesaplamalar yapılmıştır. Kinetik analiz sonuçlarına göre degredasyon mekanizmasını en iyi açıklayan model her bir örnek için bulunmuştur. Özellikle 1. Tesise ait ham atıksu numunesinin 0., 1. ve 2. derece reaksiyonlar için korelasyonun en yüksek 0.55 değerinde tespit edilmesi sonrası bu örnek için reaksiyon kinetiğinin BMG kinetik modeline 0.92 lik bir determinasyon katsayısı ile daha fazla uyumlu olduğunu göstermektedir. Buna karşın, ön çökeltmeye maruz bırakılan ilk tesise ait örneğin 2. Derece (0.98) ve BMG kinetik (0.99) modellerin her ikisine de uyumlu olduğu görülmüştür. 2. Tesise ait ham atıksu örneği ise, 2. derece kinetiğe 0.95'lik determinasyon katsayısı ile uyum sağladığı görülürken çökeltme sonrasında neredeyse BMG kinetiğine tam uyum sağladığ 1 hesaplamalarda tespit edilmiştir (Tablo 3).

$\frac{C t}{C o}=1-\frac{1}{b}$

Eşitlik 10'daki denklemde ifade edilen b ve $\mathrm{m}\left(\mathrm{dk}^{-1}\right)$ değerleri kirleticilerin bozunma değerlerini ifade eden sabit değerlerdir. $m$ değeri en yüksek oksidasyon kapasitesini gösterirken, b değeri nihai giderim oranını ifade etmektedir (Cüce vd. 2018).Yapılan deneysel kinetik hesaplamalar sonunda ön çökeltmeye tabi tutulmuş örneklerde yüksek oksidasyon değerlerine ulaşıldığı tespit edilmiştir (Tablo 3).

Tablo 3: BMG Kinetik Modeli Korelasyon Sonuçları

\begin{tabular}{llll}
\hline Numune No & $\mathbf{b}$ & $\mathbf{~ m} / \mathbf{d k}$ & $\boldsymbol{R}^{2}$ \\
\hline 1 (ham atıksu) & 1.2982 & 0.3181 & 0.9264 \\
1 (ön çökeltme) & 1.069 & 2.5262 & 0.9931 \\
2 (ham atıksu) & 1.2314 & 1.1694 & 0.9032 \\
2 (ön çökeltme) & 1.116 & 1.4297 & 0.9973 \\
\hline
\end{tabular}

1/m değeri olarak bakıldığında en yüksek başlangıç oksidasyon hızının 1. Numune için gerçekleştiği görülmüştür. Ham atıksu özelliği taşıyan ve yüksek organik madde içeriğine sahip olan bu tip atıksularda daha hızlı ve dolayısıyla kısa sürede büyük oranda bir KOİ giderimi söz konusudur. Oksidasyon hızı bakımından genel olarak her iki tesisten alınan numuneler benzerlik gösterirken, ham atıksu numunelerinin ön çökeltme sonrasında, teorik maksimum kirletici giderimi yükselmiştir (Şekil 3 ve Şekil 4). 

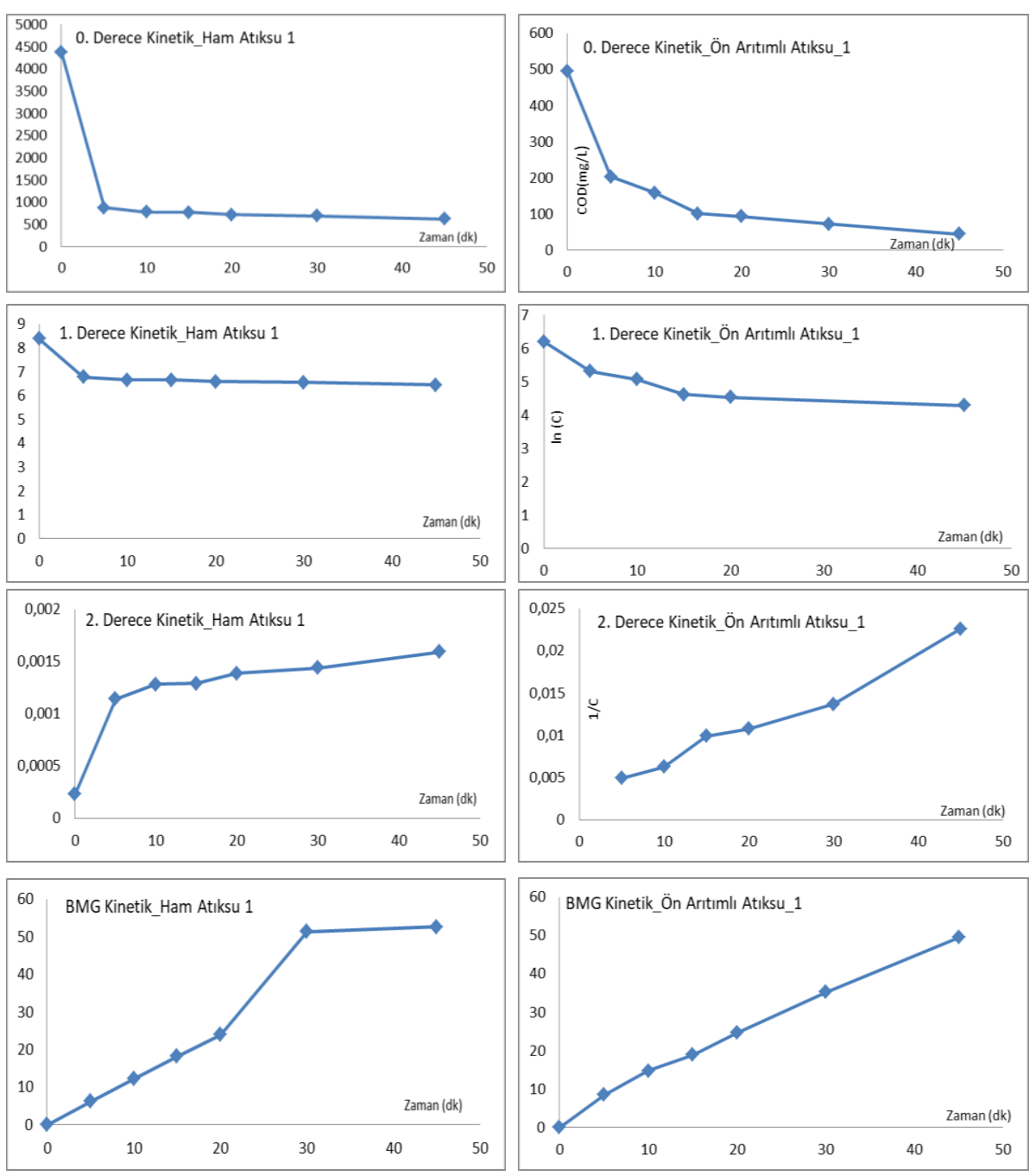

Şekil 3: Kinetik Eğilim Grafikleri (1 Nolu Atıksu örneği)

1/b değeri esas alındığında, çalışmadaki atıksular arasında en yüksek oksidasyon kapasitesine sahip olan 1 nolu tesisten alınan ön arıtımlı atıksu örneği için operasyonel parametrelerin $\left(\mathrm{H}_{2} \mathrm{O}_{2} / \mathrm{Fe}^{+2}\right.$ oranı gibi) ne kadar etkili olacağ1 tahmin edilebilir. Bir başka deyişle basit bir ön çöktürme işleminin kimyasal arıtımda kullanılacak prosese özgü kimyasal miktarlarının azaltılmasında etkili olduğu açıktır. 

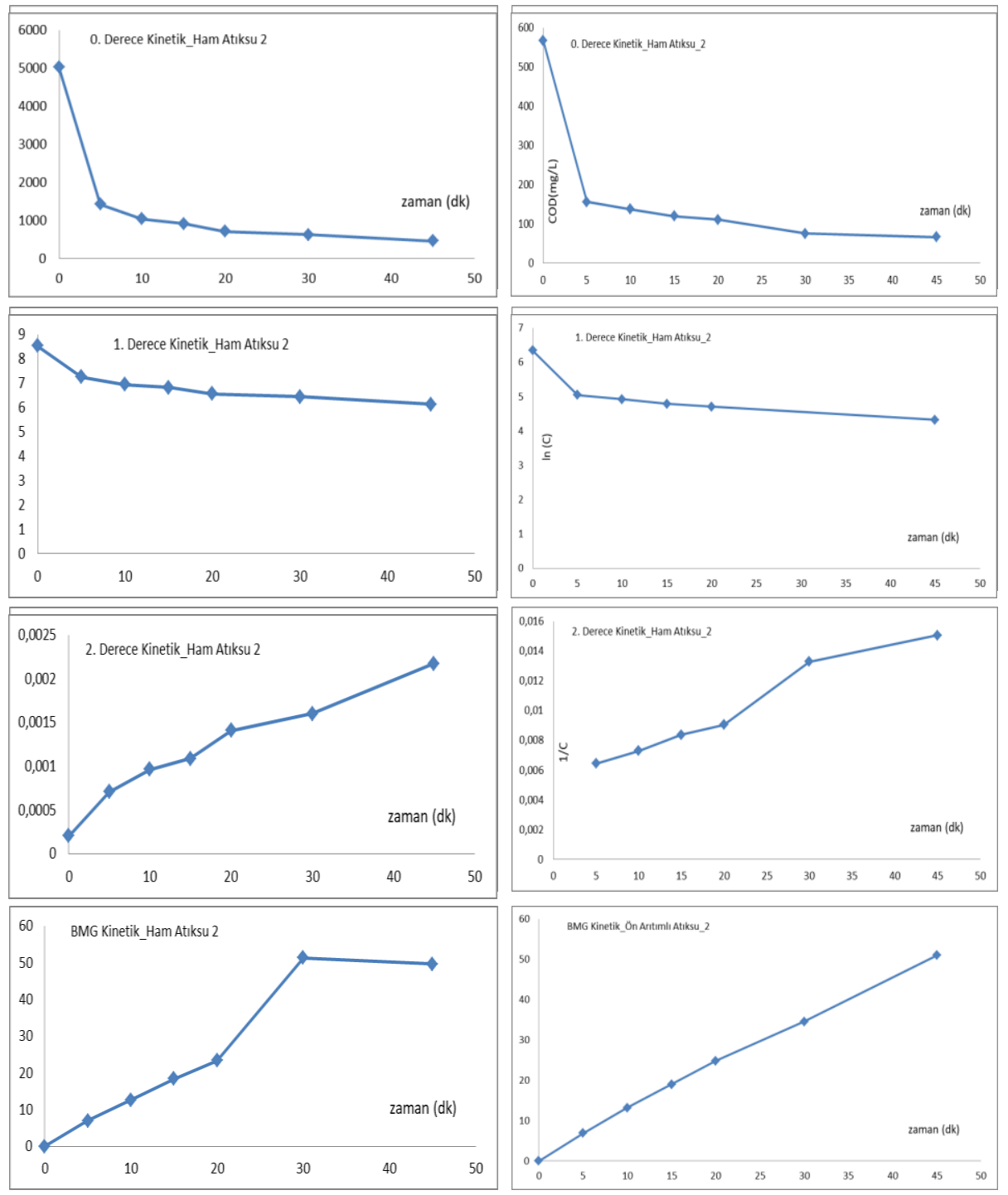

Şekil 4: Kinetik Eğilim Grafikleri (2 Nolu Atıksu Örneği)

Otomobil sektöründeki hızlı teknolojik yükseliş beraberinde trafikteki araç sayısını arttırdığından araç yıkama tesisleri de son yıllarda kapasite olarak artış göstermiş ve nispeten toksik kalıntılar içeren tesis atıksuları arıtılabilirlik açısından ülkemiz sınırları içinde de problem oluşturmaya başlamıştır. İleri oksidasyon proseslerinden biri olan ve oto yıkama atıksuları gibi küçük fakat çok sayıda bulunabilen tesislerden kaynaklı suların arıtılabilirliğinde yüksek başarı gösterebilen Fenton ve benzeri proseslere dayanan yöntemlere yönelik çalışmalar son yıllarda literatürde daha fazla yer almaya başlamıştır. Özellikle foto-Fenton veya elektro-Fenton gibi, Fenton prosesinin modifiye uygulamaları da denenmiş ve yüksek arıtım verimleri gözlenmiştir (Ganiyu vd. 2018; Davarnejad vd. 2019). Tony ve Bedri (2014), bu çalışmaya benzer şekilde oldukça yüksek KOİ giderim verimi gerçekleştirmiştir. Çalışmada pH 3.5'ta \% 97'lik bir giderim elde edilmiştir. Yine bu çalışmada olduğu gibi araba yıkama atıksuları üzerine yapılan bir Fenton + Foto Fenton çalışmasında, renk, bulanıklık, yüzey aktif madde, KOİ, yağ ve gres giderimi üzerinde durulmuştur ve \% 75 ila \% 99.6 arasında değişen giderim verimleri elde edilmiştir (Magnago vd. 2018). Benzer şekilde, Davarnejad vd. (2019)'larının yapmış oldukları çalışmada da belirttikleri üzere, $\mathrm{H}_{2} \mathrm{O}_{2} / \mathrm{Fe}^{+2}$ molar oranı arttıkça KOİ giderim oranı artmıştır. Tüm bu sonuçlar yaptığımız araştırmadan çıkan sonuçlarla paralellik göstermiştir.

\section{Sonuç}

$\mathrm{Bu}$ çalışmada, oto yıkama işletmesinden temin edilen atıksuyun arıtımında bir ileri oksidasyon yöntemi olan konvansiyonel Fenton prosesi uygulanmıştır. İzleyici parametre olarak KOİnin belirlendiği çalışmada, demir ve hidrojen peroksit dozlarının optimizasyonuna yönelik denemeler yapılmıştır. Elde edilen deneysel sonuçlar, Fenton prosesinin oto yıkama atıksularının arıtımı için oldukça verimli olduğunu göstermiştir. Ayrıca, Fenton prosesinde reaksiyonların hızlı ve yavaş oksidasyon evreleri olmak üzere iki aşamada gerçekleştiği görülmüştür. 
Birinci aşama hızlı oksidasyon olup (ilk 5 dakika), ikinci aşamada Fenton reaktanlarının (OH radikalinin oluşmasında etkin $\mathrm{Fe}^{+2}$ katalisti ve oksidant madde; hidrojen peroksit) azalmasıyla oksidasyon işleminin yavaşladığı tespit edilmiştir. Yaptığımız çalışma sonucuna göre optimum 45 dakikalık nihai sürelerde; 1 nolu tesise ait ön arıtım yapılmamış örnek için en yüksek $\mathrm{H}_{2} \mathrm{O}_{2} / \mathrm{Fe}^{+2}: 2.5$ ve \% 86 KOİ giderimi ile bulunmuş iken, ön arıtma yapılmış 2 nolu tesise ait örnek için en düşük $\mathrm{H}_{2} \mathrm{O}_{2} / \mathrm{Fe}^{+2}: 1.3$ ve \% 98'lere varan KOİ giderimi sağlanarak, klasik fenton prosesi ile oto yıkama atıksularının yüksek verimlilikte arıtılabildiği optimum değerler tespit edilmiştir.

Doğal kaynakların korunması ve sürdürülebilirliği kavramı içerisinde atıksuların geri kazanımı ve tekrar kullanımı önemli yer tutmaktadır. Dolayısıyla bu çalışmaya konu edilen oto yıkama tesislerinden şehir kanalizasyon sistemlerine aşırı bir atıksu yükü oluştuğundan ön arıtım ve / veya bütünleşik paket kimyasal veya biyolojik arıtım sistemleri kurularak arıtılmaları sağlanarak yıkama sistemine geri devir ile bağlanmaları düşünülebilir. Buna bağlı olarak, yüksek miktarda su tüketilen faaliyetlerden birisi olan araç yıkama istasyonları ve bu tesislerden kaynaklı atıksuların konvansiyonel arıtma sistemlerine alternatif olarak (uzun havalandırmalı atıksu arıtımı gibi) kimyasal oksidasyon benzeri yöntemlerle (fenton, UV, ozonlama gibi) arıtılmasının etkin, hızlı ve nispeten düşük maliyetli olabileceği göz önüne alınmalıdır. Ancak Fenton prosesinde nötralizasyon sırasında nispeten büyük $\mathrm{Fe}^{+3}$ çamur üretimi, bu arıtma tekniğginin önemli bir dezavantajdır ve pratikte endüstriyel uygulamalarını kısıtlayabilir. Bu nedenle demir kaynağı olarak proses içinde farklı heterojen katalizör (doğal mineral, sıfır değerlikli demir gibi) kullanımına dayanan yenilikçi metotlar ve foto-Fenton modifikasyonları ile çamur oluşumunu azaltamaya yönelik araştırmalar desteklenmelidir. $\mathrm{Bu}$ çalışma sonuçları ile basit prosedürüyle kullanışlı olabilen oksidant ilaveli kimyasal arıtımın etkinliği bir kez daha ortaya konulmuştur. Ayrıca, araç yıkamadan gelen suların tekrar kullanımının sürdürülebilir olarak tesis içinde sağlanabilmesinde, hızlı ve kolay adapte edilebilir Fenton gibi tekniklerin alternatif olabileceği görülmüștür. Böylelikle oto yıkama tesislerinden kaynaklı yüksek miktarlardaki atıksuların boşaltılmasıyla şehir kanalizasyon sistemine gelecek yükün azaltılması ve kirleticilerin mineralize edilerek etkisiz hale getirilmesine yönelik olarak bu çalışmadan elde edilen sonuçlar, dünyada olduğu gibi ülkemiz sınırları içinde de ileriki araştırmalara fikir vermesi açısından değerlendirilmedir.

\section{Teşekkür}

Bu çalışmanın yürütülmesinde, laboratuvar imkanlarını kullanmamıza olanak sağlayan Nevşehir Hacı Bektaş Veli Üniversitesi Çevre Mühendisliği Bölüm Başkanlığına teşekkürlerimizi sunarız.

\section{Kaynaklar}

Allan C., Pereira M., Brito N.N., (2018), Integration of treatment technologies with Fenton reagent for laboratory effluent remediation, Ambiente e Agua, An Interdisciplinary Journal of Applied Science, 13(5), doi:10.4136/1980-993x .

Argun M.E., Alver A., Karatas M., (2017), Optimization of landfill leachate oxidation at extreme conditions and determination of micropollutants removal. Desalination and Water Treatment, 90, 130-138, doi: 10.5004/dwt.2017.21241.

Argun Y.A., (2012), Reaktif Mavi 114 boyasının Fenton prosesi ile giderimi, Yüksek Lisans Tezi, Aksaray Üniversitesi Fen Bilimleri Enstitüsü, Aksaray.

Babuponnusami A., Muthukumar K., (2014), A review on Fenton and improvements to the Fenton process for wastewater treatment, Journal of Environmental Chemical Engineering, 2, 557-572.

Baştürk E., Karataş M., (2014), Advanced oxidation of Reactive Blue 181 solution: A comparison between Fenton and sonoFenton process, Ultrasonics Sonochemistry, 21, 1881-1885.

Bayat F., (2013), Zeytin karasularının elektro-fenton yöntemi ile arttılabilirliğinin incelenmesi, Yüksek Lisans Tezi, Gebze Yüksek Teknoloji Enstitüsü Mühendislik ve Fen Bilimleri Enstitüsü, Gebze.

Behnajady M.A., Modirshahla N., Ghanbary F., (2007), A kinetic model for the decolorization of CI Acid Yellow 23 by Fenton process, Journal of Hazardous Materials, 148(1-2), 98-102.

Bello M.M., Raman A.A., Asghar A., (2019), A review on approaches for addressing the limitations of Fenton oxidation for recalcitrant wastewater treatment, Process Safety and Environmental Protection, 126, 119-140.

Bhatti Z.A., Mahmood Q., Raja I.A., Malik A.H., Wu D., (2011), Chemical oxidation of carwash industry wastewater as an effort to decrease water pollution, Journal of Physics and Chemistry of the Earth, 36, 465-469.

Boluarte I.A.R., Andersen M., Pramanik B.K., Chang C.Y., Bagshaw S., Farago L., Jegatheesan V., Shu L., (2016), Reuse of car wash wastewater by chemical coagulation and membrane bioreactor treatment processes, International Biodeterioration \& Biodegradation, 113, 44-48.

Brito, N.N., Paterniani, J.E.S., Brota, G.A., Pelegrini, R.T., (2010), Ammonia removal from leachate by photochemical process using H2O2, Ambiente \& Água-An Interdisciplinary Journal of Applied Science, 5(2), 51-60.

Chen Y., Fan T., Wang L., Cheng T., Chen S., Yuan M., Cheng S., (2020), Application of Fenton method for the removal of organic matter in sewage sludge at room temperature, Sustainability, 12, 1518, doi:10.3390/su12041518.

Chu L., Wanga J., Dong J., Liu H., Sun X., (2012), Treatment of coking wastewater by an advanced Fenton oxidation process using iron powder and hydrogen peroxide, Chemosphere, 86, 409-414.

Collivigranelli M.C., Pedrazzani R., Sorlini S., Abba A., Bertanza G., (2017), $\mathrm{H}_{2} \mathrm{O}_{2}$ based oxidation processes for the treatment of real high strength aqueous wastes, Sustainability, 9, 244, doi:10.3390/su9020244.

Cüce H., Aydın Temel F., (2021), Classical-Fenton and photo-Fenton oxidation of wastewater arising from cosmetic automobile care products. Environmental Progress \& Sustainable Energy, e13701, doi:10.1002/ep.13701 . 
Cüce H., Yakut Ş.M., Özak E., (2018), Halı yıkama atıksularının ileri oksidasyon prosesi ile arıtımı, Bitlis Eren Üniversitesi Fen Bilimleri Dergisi, 7(2), 339-348.

Davarnejad R., Sarvmeili K., Sabzehei M., (2019), Car wash wastewater treatment using an advanced oxidation process: A rapid technique for the COD reduction of water pollutant sources, Journal of the Mexican Chemical Society, 63(4), 164-175.

Dolay E., (2009), Emaye kaplama endüstrisi atıksularının fenton prosesi ile arıtılması, Yüksek Lisans Tezi, Selçuk Üniversitesi Fen Bilimleri Enstitüsü, Konya.

Emamjomeh M.M., Jamali H.A., Naghdali Z., Mousazadeh M., (2019), Efficiency of electrocoagulation, sedimentation and filtration hybrid process in removing chemical oxygen demand and turbidity from carwash industrial wastewater: Optimization by response surface methodology. Journal of Mazandaran University of Medical Sciences, 29(174), 106-120.

Ertugay N., Filiz N.A., (2017), Removal of COD and color from Direct Blue 71 azo dye wastewater by Fenton's oxidation: Kinetic study, Arabian Journal of Chemistry, 10, 1158-1163.

Gamaralalage D., Sawai O., Nunoura T., (2019), Reusing the generated sludge as Fe source in Fenton process for treating crepe rubber wastewater, Journal of Material Cycles and Waste Management, 21(2), 248-257.

Ganiyu S.O., Huong Le T.X., Bechelany M., Oturan N., Papirio S., Esposito G., Hullebusch E., Cretin M., Oturan M.A., (2018), Electrochemical mineralization of sulfamethoxazole over wide $\mathrm{pH}$ range using $\mathrm{Fe} \mathrm{II}^{I I} \mathrm{e}^{I I I} \mathrm{LDH}$ modified carbon felt cathode: Degradation pathway, toxicity and reusability of the modified cathode, Chemical Engineering Journal, 350, 844-855.

Gokkus O., Ciner F., (2010), Investigation of color and COD removal from wastewater containing disperse Yellow 119 and disperse Red 167 using Fenton oxidation process, Journal of the Faculty of Engineering and Architecture of Gazi University, 25(1), ss.4955.

Gönder Z.B., Balcioglu G., Vergili I., Kaya Y., (2017), Electrochemical treatment of carwash wastewater using Fe and Al electrode: techno-economic analysis and sludge characterization, J. Environ. Manage. 200, 380-390, doi:10.1016/j. jenvman.2017.06.005.

Gönder Z.B., Balcıoğlu G., Vergili I., Kaya Y., (2020), An integrated electrocoagulation-nanofiltration process for carwash wastewater reuse. Chemosphere, 253, 126713, doi: 10.1016/j.chemosphere.2020.126713.

Hamada T., Miyazaki Y., (2004), Reuse of carwash water with a cellulose acetate ultrafiltration membrane aided by flocculation and activated carbon treatments, Desalination, 169(3), 257-267.

Kalipci E., Sahinkaya S., Dortkol M., Aras S., (2016), Decolorization of basic textile dyes using a novel adsorbent modification method: Ultrasonic-acid modification. International Journal of Environmental Research, 10(1), 31-40.

Kashi G., Younesi S., Heidary A., Akbarishahabi Z., Kavianpour B., Rezaei Kalantari R., (2021), Carwash wastewater treatment using the chemical processes, Water Science and Technology, doi:10.2166/wst.2021.206.

Kaya Ş., Aşçı Y., (2019), Evaluation of color and COD removal by Fenton and photo-Fenton processes from industrial paper wastewater, Iğdır Üniversitesi Fen Bilimleri Enstitüsü Dergisi, 9(3),1539-1550.

Kocakaplan N., Ertugay N., Malkoç E., (2014), Fenton ve Fenton-benzeri ileri oksidasyon yöntemleri ile Acid Yellow 36 boyar maddesinin giderimi, Iğdır Üniversitesi Fen Bilimleri Enstitüsü Dergisi, 4(1), 41-48.

Kumar K., Vasanth K., Porkodi Rocha F., (2008), Langmuir-Hinshelwood kinetics-a theoretical study, Catalysis Communications 9(1), 82-84.

Lan W., Gang G.E., Jinbao W.L., (2009), Biodegradation of oil wastewater by free and immobilized Yarrowia lipolytica W29, Journal of Environmental Sciences, 21(2), 237- 242.

Lau W.J., Ismail A.F., Firdaus S., (2013), Car wash industry in Malaysia: Treatment of car wash effluent using ultrafiltration and nanofiltration membranes, Separation and purification Technology, 104, 26-31.

Lin S.H., Lo C.C., (1997), Fenton process for treatment of desizing wastewater, Water Res. 31:2050-2056

Magnago R.F., Berselli D., Medeiros P., (2018), Treatment of wastewarer from car wash by Fenton and photo-Fenton oxidative processes. J. Eng. Sci. Technol, 13(4), 838-850.

Moazzem S., Ravishankar H., Fan L., Roddick F., Jegatheesan V., (2020), Application of enhanced membrane bioreactor (eMBR) for the reuse of carwash wastewater, Journal of environmental management, 254, 109780, doi: 10.1016/j.jenvman.2019.109780.

Oknich J., (2002), Handbook for the perceived environmental impact of car washing. Ramsey-Washington Metro Watershed District. Washington.

Onaran G., Gürel L., Argun H., (2020), Detoxification of waste hand paper towel hydrolysate by activated carbon adsorption. International Journal of Environmental Science and Technology, 17(2), 799-808.

Özdemir C., Öden M.K., Şahinkaya S., Kalipci E., (2011), Color removal from synthetic textile wastewater by sono-fenton process. Clean-Soil, Air, Water, 39(1), 60-67.

Panizza M., Cerisola G., (2010), Applicability of electrochemical methods to carwash wastewaters for reuse. Part 2 : Electrocoagulation and anodic oxidation integrated process, Journal of electroanalytical chemistry, 638(2), 236-240.

Sarmadi M., Foroughi M., Saleh H.N., Sanaei D., Zarei A.A., Ghahrchi M., Bazrafshan E., (2020), Efficient technologies for carwash wastewater treatment: a systematic review. Environmental Science and Pollution Research, 27, 34823-34839.

Şentürk İ., Yıldız M.R., (2020), Highly efficient removal from aqueous solution by adsorption of Maxilon Red GRL dye using activated pine sawdust. Korean Journal of Chemical Engineering, 37, 985-999.

Sychev A.Y., Isak V.G., (1995), Iron compounds and the mechanism of the homogeneous catalysis of the activation of $\mathrm{O}_{2}$ and $\mathrm{H}_{2} \mathrm{O}_{2}$ and of the oxidation of organic substrates, Russ. Chem. Rev. 64, 1105-1129.

Tony M.A., Bedri Z., (2014), Experimental design of photo-Fenton reactions for the treatment of car wash wastewater effluents by response surface methodological analysis, Advances in Environmental Chemistry, Vol. 2014, 8ss, doi:10.1155/2014/958134.

Tony M.A., Lin L.S., (2020), Performance of acid mine drainage sludge as an innovative catalytic oxidation source for treating vehicle-washing wastewater, Journal of Dispersion Science and Technology, 1-11, doi:10.1080/01932691.2020.1813592.

Üstün G.E., Solmaz S.K.A., Morsünbül T., Azak H.S., (2010), Advanced oxidation and mineralization of 3-indole butyric acid (IBA) by Fenton and Fenton-like processes, Journal of hazardous materials, 180(1-3), 508-513. 